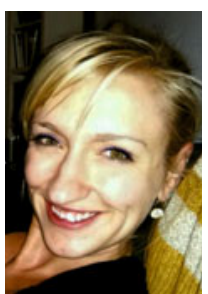

Yvonne Göpel

2005-2010 Biologiestudium,

Universität Göttingen; dort

2010-2013 Promotion am Insti-

tut für Mikrobiologie und Genetik

bei PD Dr. B. Görke. Seit 2013

Postdoktorandin, Universität

Wien.

\title{
VAAM-Promotionspreis 2014
}

\section{Drei sind (k)einer zu viel: Wie sRNAs die Zellwandsynthese steuern}

\author{
YVONNE GÖPEL \\ VIENNA BIOCENTER, UNIVERSITÄT WIEN
}

DOI: $10.1007 / \mathrm{s} 12268-015-0545-3$

(c) Springer-Verlag 2015

- Kleine regulatorische RNAs (sRNAs) sind wichtige posttranskriptionelle Regulatoren der Genexpression in allen Domänen des Lebens und wirken in verschiedenen physiologischen Prozessen [1]. Kleine RNAs agieren meist über Basenpaarung mit ihren Zieltranskripten und beeinflussen deren Translation und/oder Stabilität.

In Escherichia coli reguliert die sRNA GImZ die Expression der Glukosamin-6-phosphatSynthase (GlmS) - ein Schlüsselenzym im Aminozucker-Stoffwechsel. GlmS bildet Glukosamin-6-phosphat (GlcN6P), einen wichtigen Vorläufer im Aufbau der Zellwand. In der glmS-mRNA liegt die Ribosomenbindestelle in einer Sekundärstruktur verborgen, wodurch die Translation nur ineffizient erfolgt. Mithilfe des RNA-bindenden Proteins Hfq kann GlmZ mit glmS Basen-paaren, diese Struktur somit aufbrechen und die Translation ermöglichen [2]. GlmZ selbst unterliegt einer Prozessierung, wodurch diese sRNA

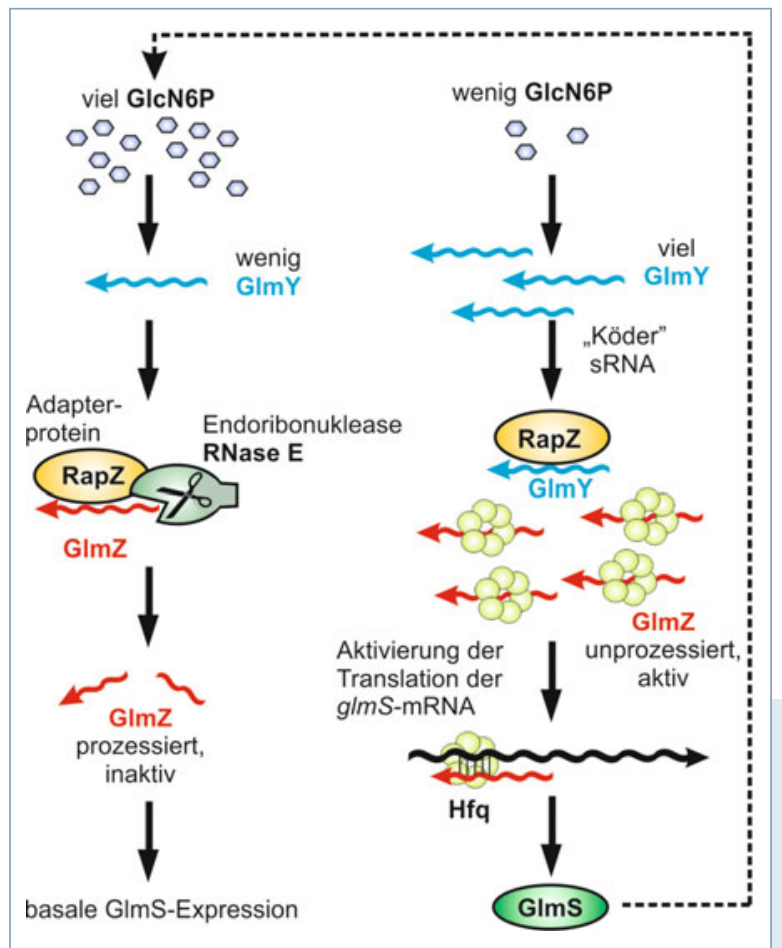

abgebaut wird. Interessanterweise wird für diesen Prozess das Protein RapZ benötigt, ein bis dato noch nicht charakterisiertes, konserviertes Protein. Wenn GlcN6P in der Zelle limitierend ist, kann der Abbau von GlmZ durch eine zweite, homologe sRNA - GlmY verhindert werden (Abb. 1).

Im Rahmen meiner Doktorarbeit gelang es, den Mechanismus dieser in Enterobakterien konservierten sRNA-Kaskade aufzuklären und die Funktion des RapZ-Proteins zu entschlüsseln [3, 4]. RapZ ist ein RNA-bindendes Protein, das GlmY und GlmZ bindet. Wird die Aktivität des Enzyms GlmS nicht benötigt, bindet RapZ an GImZ und rekrutiert die Endoribonuklease RNase E zum Abbau der sRNA. RNase E ist eine essenzielle, globale Endoribonuklease. An ihrer C-terminalen Domäne organisiert RNase E einen Multienzymkomplex, das Degradosom, das am Abbau einer Vielzahl von RNAs beteiligt ist. Im Gegensatz dazu kann durch Interaktion der N-terminalen katalytischen Domäne von RNase E mit RapZ ganz gezielt ein Transkript, nämlich die sRNA GlmZ, abgebaut werden. RapZ agiert demnach als Adapter, der eine generelle RNase mit einem spezifischen Substrat zu dessen Abbau zusammenführt [4].

Sinkt der GlcN6P-Spiegel, wird die Aktivität des synthetisierenden Enzyms GlmS essenziell. Unter diesen Bedingungen akkumuliert die kleine RNA GlmY und titriert RapZ. GlmY übt dabei die Rolle eines Anti-Adapters aus und „ködert“ RapZ. Somit wird verhindert, dass GlmZ prozessiert werden kann. GlmZ aktiviert dann die Expression von glmS, was zum Anstieg der GlcN6PMenge führt. GlcN6P inhibiert zunehmend die GlmY/GlmZ-Kaskade. Die Regulation der glmS-Expression unterliegt also einer negativen Rückkopplung. Über diesen komplexen Mechanismus aus drei Komponenten, zwei hierarchisch wirkenden, homologen sRNAs und einem Adapterprotein, wird ein Gleichgewicht an GlcN6P in der Zelle eingestellt (Abb. 1).

\section{Danksagung}

Mein Dank gilt meinem Doktorvater Boris Görke, unseren Kollaborationspartnern und der DFG sowie dem Dorothea-Schlözer-Programm der Universität Göttingen für die finanzielle Unterstützung.

\section{Literatur}

[1] Storz G, Vogel J, Wassarman KM (2011) Regulation by small RNAs in bacteria: expanding frontiers. Mol Cell 43:880-891

[2] Göpel Y, Khan MA, Görke B (2014) Ménage à trois: posttranscriptional control of the key enzyme for cell envelope synthesis by a base-pairing small RNA, an RNase adaptor protein, and a small RNA mimic. RNA Biol 11:433-442

[3] Göpel Y, Lüttmann D, Heroven AK et al. (2011) Common and divergent features in transcriptional control of the homologous small RNAs GImY and GlmZ in Enterobacteriaceae. Nucleic Acids Res 39:1294-1309

[4] Göpel Y, Papenfort K, Reichenbach B et al. (2013) Targeted decay of a regulatory small RNA by an adaptor protein for RNase E and counteraction by an anti-adaptor RNA. Genes Dev 27:552-564

\section{Korrespondenzadresse:}

Dr. Yvonne Göpe

Universität Wien

Vienna Biocenter

Max F. Perutz Laboratories

Department of Microbiology, Immunobiology and Genetics

Dr. Bohr-Gasse 9

A-1030 Wien

Tel.: +43-(0) 1-4277-74610

yvonne.goepel@univie.ac.at
Die Kaskade aus den sRNAs GImY und GImZ und dem Adapterprotein RapZ steuert die Expression der Glukosamin-6-phosphat-Synthase (GImS) in Escherichia coli. Ist viel Glukosamin-6-phosphat (GIcN6P) vorhanden, wird GImZ durch RapZ und die Endoribonuklease RNase E abgebaut. Wird GlcN6P benötigt, führt die Akkumulation der homologen sRNA GImY zur Stabilisierung von GImZ. 